\title{
The Road to Achieving a Critical Mass of Sociologists and Anthropologists in the World Bank
}

\author{
Charles Weiss
}

A succession of dominant academic and applied disciplines influenced the intellectual paradigm, policies, and lending operations of the World Bank before, during and immediately after the presidency of Robert McNamara. The account that I document below about one part of this disciplinary succession and intellectual expansion of the World Bank's outlook is based on the author's work in the Bank between 1971 and 1985, during which time I served as the Bank's first Science and Technology Adviser.

This position was located in the front office of the Bank's vice president for policies and projects. My job was to promote innovative applications of science and technology in the projects financed by the Bank, and to develop ways to use its investment lending for building local scientific and technological capacity in the developing countries. ${ }^{1}$ This essay focuses on what is usually called 'McNamara's time' at the World Bank, which until today remains in my view (as well as in the ranking of other veteran staff members, and of some Bank historians) the most remarkable period in the history of the World Bank.

In this essay, I distinguish three broad phases in the succession of professional disciplines that influenced most strongly the Bank's intellectual framework. The first phase was the pre-McNamara era between 1945 and 1970, which was dominated by engineers and financial specialists. The second broad phase was the decade of the 1970 s, characterized by a profound substantive shift in the Bank's thinking and in its

\footnotetext{
${ }^{1}$ For a fuller treatment of these activities, see Charles Weiss, Science and Technology at the World Bank, 1968-1983, History and Technology, 22, 81-104 (2006), and Charles Weiss, The World Bank's Support to Science and Technology, Science, 227, 261-5 (1985).
}

C. Weiss (殴

School of Foreign Service, Georgetown University, Washington, DC, USA

e-mail: weissc@georgetown.edu 
staff composition, with economics becoming the preeminent science and economists becoming the predominant professional group in the Bank. Within the large group of economists, a more granular analysis would also distinguish a division into microand macro-economists. Due to the microeconomists' close involvement with technical specialists in the design of "project packages" and the formulation of sectorial policies, they initially had a stronger influence in the Bank than their macroeconomic colleagues.

The third phase started in the early 1980s, when the advent of structural adjustment programs shifted established the dominance of the macro-economists. But this third phase also saw the gradual formation of a new professional group, the Bank's community of professional social and environmental specialists located and embedded across the Bank throughout the operational staff. The presence and influence of the Bank's first staff members with expertise in sociology and anthropology started quite late, only in the mid-1970s. A few pioneers and forerunners of this new community gained some place inside the Bank's headquarters in the 1970s, with McNamara's direct support. But only in the 1980s did they gain some critical mass and the kind of positions on the Bank's organogram that afforded them intellectual power and influence over the World Bank's processes and products. Their roles in the Bank started to have a gradually growing impact on the Bank's overall model of doing business - its development paradigm — during the third of the phases outlined above, the decade of the 1980s and beyond.

The World Bank hired its first in-house sociologist, Michael Cernea, only in 1974, followed by very few other trained social specialists over the next 4 years. They were: Gloria Scott; a young professional, Jacomina de Regt; Maritta KochWeser, who started in 1977 as a consultant; and Gloria Davis. Only during the third phase did the hiring of social specialists pick up pace and begin to move gradually toward gaining the critical mass they needed to work at the Bank's larger scale, rather than only intervening project-by-project.

This essay describes in detail a single critical moment in 1979-1980 that gave a deliberate impetus toward creation of a critical mass, roughly at the passage from phase two to phase three. I am proud to have been part of this event.

\section{McNamara's Knowledge Revolution}

On becoming President of the World Bank in 1968, Robert McNamara inherited an organization whose major function was to lend for infrastructure projects in its member developing countries, using much the same standard technology and project design as would be normal in advanced countries. Its lending was limited to a billion dollars a year, the most his predecessors thought that world financial markets would be willing to allow it to borrow. The operating staff that McNamara found in the Bank - the staff concerned with the lending program and the projects for which the Bank lends-consisted mainly of engineers and financial analysts.

Throughout the 1970s and early 1980s, techno-economic analysis was both the Bank's greatest operational strength and also its greatest operational weakness. It 
gave rigor and objectivity to the evaluation of projects and the analysis underlying sectorial policies. At the same time, it created an intellectual atmosphere and organizational culture in which the non-economic social sciences, specifically applied sociology and anthropology, were not seen as areas of knowledge needed for the activity, objectives and mission of the Bank.

The most important change initiated by Robert McNamara shortly after he became President was to re-orient the World Bank's policy and programs toward the major objective of reducing poverty in the developing world. No financial institution had ever before tried to fight poverty on such a global scale. He announced that a major objective of the Bank would be to fight poverty in its borrowing countries, first through a new program of multi-component "rural development" projects, predominantly in agriculture, and later through a program of "urban development," chiefly low-cost housing. No one knew precisely how to meet this exciting challenge, but the staff embraced the new objective and its moral underpinnings, and were willing to try.

To achieve the new objective of reducing poverty, McNamara put his indelible imprint on the Bank with a series of revolutionary changes. He increased the lending portfolio to some $\$ 16$ billion and the staff to 5700 . They brought to the borrowing countries, most of which had only recently freed themselves from being colonies to become independent countries, a high degree of professionalism, honesty and freedom from motivations of private profit.

McNamara's deeper and subtler changes in the disciplinary composition of the Bank operational and development policy staff were three-fold: first, to embed economists at all levels of the Bank; second, to recruit smart, ambitious, under-30year-old "young professionals" with training in economics or management (almost never in engineering, technology, or the non-economic social sciences) to spearhead his new initiatives and to challenge experienced, older professionals to think in new ways; and third, to staff the Bank's project divisions- the staff directly responsible for identifying, preparing, appraising, and supervising projects, and evaluating them after their completion - in such a way that technical experts (agronomists, infrastructure engineers, urban designers, etc.) were required to work together with applied microeconomists in what became known, somewhat grumpily, as "creative tension."

Within each regional staff, these operating departments were organized in parallel in two types of divisions: "program" and "project". The first were staffed mostly by macroeconomists, whose function was to analyze a country's economy and draw up broad plans for the size of its lending program, identify the sectors (agriculture, industry, etc.) in which priority lending was to be provided, and the broad outlines of possible projects for Bank financing. The Bank's largest units were the project divisions that oversaw the preparation and design of projects by the borrowing country, carried out with more or less help from Bank staff and consultants, depending on the country's level of expertise. The Bank then appraised these projects through missions comprising economists and technical specialists, but very seldom, at that time, a social or environmental specialist. The project divisions were also in charge of supervising project implementation on the ground by the 
borrower's agencies, while the program divisions were responsible for making sure that the Bank's projects added up to a coherent strategy and met the lending targets for each country, the latter being one of McNamara's most important management goals and his key measure of success.

Project plans drawn up by technical experts for consideration for Bank lending were subjected to an increasingly elaborate discipline of cost/benefit analysis, resulting in an unmatched level of sophistication in techniques of quantitative, techno-economic cost/benefit analysis. The scope of this analysis was construed quite broadly, as long as project costs and benefits could be expressed quantitatively and translated into money equivalents. The quantified benefit of a project, for example, might have consisted of the value of increased rice production resulting from an irrigation project, the value of the time saved by commercial truckers resulting from the construction of a road, or the value of the increased earnings of the graduates produced by an education project. If the calculated benefits of an investment, suitably discounted, exceeded its discounted costs, it was considered to be beneficial at the scale of the entire society.

The Bank's economic and technical specialists were able professionals, often world-class experts with many years of senior experience in their respective specialties, giving the Bank staff the sobriquet of an 'army of colonels.' Their economic and technical analyses gave rigor and objectivity to the evaluation and justification of projects, and blocked many a resource-wasting boondoggle from being approved for financing.

However, this techno-economic approach also had its severe downsides, which at that time were not yet perceived or regarded as such. For instance, the unilateral use of cost/benefit assessment at the level of the entire society was devoid of an equally necessary distribution analysis. (Some Bank economists ${ }^{2}$ actually worked out techniques for this purpose, but these were never put into practice on a substantial scale.) This prevented the Bank from assessing what proportion of the benefits were accruing to the poorest, or more generally, how the gains and the pains of the projects it financed were distributed within the country's population. Without this kind of analysis, the Bank's ability to assess the effects of the projects it financed on poverty was unequal to its ambition of reducing poverty.

\section{Development Policy: A Quasi-monopoly of the Economist ?}

The Bank's organizational culture and disciplinary perspectives were substantially limited by the anomaly that the non-economic social sciences, specifically sociology, anthropology, political science, and social psychology, were not regarded as

\footnotetext{
${ }^{2}$ Lynn Squire and Herman van der Tak, Economic Analysis of Projects (Baltimore: Johns Hopkins Press for the World Bank, 1975), available at http://documents.worldbank.org/curated/en/ 954731468156870423/pdf/794880PUB0Econ00Box377372B00PUBLIC0.pdf
} 
areas of knowledge needed for the activities, objectives and mission of the Bank. Its emphasis on costs and benefits that could be monetized and quantified encouraged the tendency to overlook, or directly neglect, important adverse social and environmental effects that were hard to monetize, as for example the human costs of population displacement by infrastructure or the environmental costs of loss of biodiversity. Feeding into and reproducing this overly narrow view was the almost exclusive emphasis on recruitment of staff with expertise in economics or with senior experience in a specific area of technology. A generalist on the Bank staff-especially a young generalist - tended almost always to be an economist. Indeed, the hiring of young staff with training in applied science or engineering was specifically discouraged.

This narrowness entailed a cost at the policy level. The formulation of new operational policies and guidelines that controlled the areas in which the Bank would lend for projects, and the intellectual framework for the resulting operations remained almost entirely the guarded province of the Bank's economic staff. Few subjects were deemed worthy of serious attention unless their importance could be justified with economic arguments. Economics was the sovereign body of knowledge that claimed jurisdiction over the policies of the Bank, and it was economics that controlled the pattern of all the Bank's policy analyses. In the terms of organizational theory, economics was the dominant discipline, causing the Bank's understanding of the complexities of development at the grassroots to suffer limitations that should have been unacceptable both in the Bank's theory and in the Bank's practice.

This one-dimensional approach relegated to secondary importance (or worse, to complete ignorance and neglect) dimensions and factors studied by non-economic disciplines like sociology and anthropology, and limited the potential contributions of environmentalists and social specialists. Recommendations coming from such disciplines were more difficult to quantify and monetize. Social and environmental impacts were also longer run in nature and hence vulnerable to discounting. Again reflecting the dominance of economic concepts, poverty was defined strictly by income levels and income distribution. Considerations of democracy, of the agency of the project area's population, and human rights were excluded, by the thendominant narrow interpretation of the Bank's charter-the "articles of agreement"- that only economic considerations should guide its policy and lending decisions.

The models that dominated the economic discipline in the 1970s and later had important blind spots. First of all, many development economists were trained and socialized to believe that liberalization, privatization, "getting prices right," and "letting the market work"- the core of what eventually became the Washington Consensus - were all that was needed for successful development. If these principles were implemented, so the received wisdom went, other imbalances would be straightened and fall into place.

At the same time, important bodies of knowledge relevant to inducing development—environment, health, and education, to name but a few-were themselves in early stages of conceptual development, while the capacities of disciplines like 
anthropology and sociology to use their knowledge in an applied manner were also incipient. They had their own reverse blind spots, especially regarding economic variables, and lacked operational translations for applying their insights to practical situations. This meant that the concepts and approaches that advocates would have needed in order to demonstrate the importance of these fields to Bank operating and policy staff were underdeveloped and at a disadvantage to compete organizationally with the dominant discipline of economics. They were therefore in a weak position to challenge the ruling economic paradigm. The recognition that economic growth could also have serious adverse social and environmental impacts, especially in developing countries, was also very limited or absent.

On the positive side, the pressure to meet the economic arguments put forward by the Bank and by financial officials in developing countries also resulted in advances more in the economic than in the non-economic disciplines. Once Bank economists and their outside colleagues became convinced of the importance of a subject-often as a result of outside pressure - they made important contributions in laggard disciplines of applied economics. Some members of neglected disciplines also tended to build bridges to the economic profession from their side. Pressed to demonstrate the economic validity of their concerns, sociologists and anthropologists gained new appreciation for the economic causes and impacts of the social changes they predicted or observed. Anthropologists learned to characterize the destruction of cultural heritage, or the failure to provide adequate compensation to farmers displaced by an irrigation project, as externalities that must be recognized as a real part of a project's cost.

\section{Entrepreneurial Advisers in Social Disciplines}

Environment, sociology, and to a lesser extent women's issues presented the danger that a project that neglected them could produce a well-publicized disaster, with concomitant, unwelcome negative repercussions on the Bank's reputation and ability to get funding. In 1970, the Bank took the positive step of creating an Office of Environmental Affairs under James Lee, which aimed to use for Bank-financed projects environmental standards proposed by the US Environmental Protection Agency. Lee's office reviewed the design of projects being considered for funding in an attempt to ensure compliance with these standards, which was more than other development assistance institutions did at the time. ${ }^{3}$ But the Bank did not have an overall environmental policy able to inform the attention to the environmental impact of individual projects and was still far from incorporating environmental considerations into its country analyses. The Bank's staff at large was inadequately educated not only on social matters but also on environmental matters; many still

\footnotetext{
${ }^{3}$ See, for example, Robert E. Stein, Banking on the biosphere? : Environmental procedures and practices of nine multilateral development agencies (Lexington MA: Lexington Books, 1979).
} 
regarded environmental protection (and Lee's office) as a constraint, a passing fashion, or even an obstacle rather than as a worthy objective.

The first Bank unit that decided to search for and appoint a professionally credentialed sociologist was the experimental division created by McNamara to test new models for projects aimed to reduce poverty. That Department was led by Montague Yudelman, Leif Christoffersen and Don Pickering, and included some of the Bank's best agricultural specialists and economists. They felt that in order to reach and understand the poor, the Department would also need a professional trained in social sciences, capable of translating sociological theory for applied purposes in real-life project situations, and being intellectually action-oriented (the long search for such person is described in this book's essay by Christoffersen). Michael Cernea became the first ever sociologist on the Bank's full-time staff. Indeed, as I learned later, when he was hired his recruiters and colleagues called him the "Ambassador for Sociology," and said that he had to demonstrate that this social science was useful to the Bank. (I had had a similar challenge when I was hired as the Bank's first Science and Technology Adviser.) Nonetheless, to begin with, Cernea was initially offered a term contract. Only after he was able to prove that his sociological knowledge was valuable for practical purposes was he tenured. For a few years, he remained the Bank's only in-house staff sociologist. It took some time until, slowly, the idea that other sociologists might be brought in began to be contemplated.

\section{A Request for Help on the Issue of Critical Mass}

My responsibility as Science and Technology Advisor in the Bank's center was to be alert to new developments in science and technology that could be relevant to the Bank's work, and then to facilitate bringing the new knowledge to the attention of Bank staff that could evaluate and use them.

At that time, however, anthropology and sociology were not on my screen. Social science disciplines other than economics were not seen at all as part of the knowledge used by the Bank. Yet I welcomed the first hiring of a sociologist. For me it symbolized not just a new individual staff member, but also a new Bank window opened to a still unused domain of science knowledge and research.

As time went on, I heard about some of the new things that Cernea was doing in the Bank's poverty reduction projects, and some times also met with him, to keep up with developments. One of these, for instance, was the design of a system for monitoring and evaluation of an entire category of Bank projects in India and other countries (on agricultural extension and its impact on farmer behavior). This was the first design of its kind in the Bank and was issued as a World Bank publication-rather unusual for a young staff member who had joined the Bank only recently. I also knew that he was cultivating allies among like-minded staff wherever they could be found, convening informal meetings of these staff to discuss issues of shared concern, inviting outside anthropologists or sociologists to give 
seminars on projects they were researching, or publishing articles about, and advocating for the use of more social specialists in the Bank's projects. It was much as I had done myself, on relevant new development in science, when I was establishing my role as the Bank's first Science and Technology Adviser, and continued to do thereafter.

Toward the end of 1978, Michael approached me, proposing a talk over lunch about sociology in the Bank. He had a plan and wanted to enlist my help. Cernea was content and optimistic about his own work, but he was rather upset that the hiring of other social specialists in the Bank was for all practical purposes blocked by inertia. He pointed out the contradiction between the increasing interest at the center of the Bank for sociological competence, on the one hand, and the unwillingness of the Bank's regional departments to allocate slots to hiring sociologists, on the other. $\mathrm{He}$ described specific obstacles he had encountered and without mincing words said that there were more than a few prejudiced middle-level managers who were openly opposed to dealing with what they termed "soft sciences" and "warm-hearted but cloud-dwelling people", who—as they believed —had little tangible to contribute to a hard-nosed economic agency like the World Bank.

Cernea had reached the conclusion that, to the contrary, the Bank needed to purposively go out and hire more social specialists because, he said, the kind of social issues and problems on which he had to work in his Division's projects were present, more or less, in multiple other comparable projects across the Bank. But there were no trained social specialists in those other Divisions and no willingness to hire staff with such professional profile. He explicitly argued that 'a minimum critical mass of professionally trained social specialists needed to be created in-house to work day in and day out to address the many social and cultural issues confronted by the Bank in every development project'. Only sociology and anthropology could provide such knowledge and skills for what he termed as "financially induced and managed development." Undeterred by the resistance he met, he asserted his firm belief that the Bank "needed social specialists in most Bank projects, and at every key stage of the project cycle". In sum, Cernea directly asked me point blank if, in my capacity as Science and Technology Advisor, I could support his advocacy for more applied social scientists in the Bank.

It became very clear why he had asked for our lunch. He had a point. I did not have any advice on the spot, though I was left with the sense that he was right; he had clearly come up against a textbook case of the syndrome familiar to students of the diffusion of innovation processes.

I could only empathize, and I promised to think about what he had said.

In December 1978, over Christmas vacation, I wrote a two-page memo to Warren Baum, the Bank's Vice President for Projects and Policies and its champion for project quality. My memo recommended that the Bank increase the proportion of staff trained in non-economic social sciences, especially anthropology and sociology. To support my argument, I made a metaphoric reference to the process of "adaptive radiation" that Charles Darwin observed among the finches of the Galapagos Islands. I also made two pragmatic organizational suggestions: that sociologists be diffused throughout operational departments, not only located in 
the center; and that recruiting should be encouraged through the higher levels in the Bank's regional vice-presidencies if this was necessary to overcome the hesitation or reluctance of mid-level managers.

Below are excerpts from my Jan. 3, 1979 memo to our vice president, Mr. Baum, in which I articulated my argument; I also ensured, in line with Bank rules, the prior agreement of the Senior Economist and Policy Adviser, Herman van der Tak, Baum's deputy and my immediate manager and mentor. Below are key excerpts from my memorandum, fortunately preserved, titled 'Disciplinary Balance of Bank Staff':

The Bank's highly skewed composition by discipline is one of its major long-run internal problems. The preponderance of Bank staff, both at working and managerial levels, are economists and engineers (in the general sense of applied technologists, to include agronomists, highway planners, etc.) Moreover, a generalist—especially a young generalist - is in the Bank almost by definition as economist. [...]

The Bank needs more than engineering and economic insights. And it is remarkable how many it does succeed in getting. This phenomenon has an interesting analog in evolutionary biology. In the field studies that provided the empirical basis for his theory of evolution, Charles Darwin found that the finches, the only major group of birds to have colonized the Galapagos Islands, had evolved in many directions to fill ecological niches that elsewhere were filled by owls, eagles, sparrows, etc., a process now known as adaptive radiation.

By the same process, the Bank has evolved economists and engineers who do their best to think and act like sociologists, anthropologists, political scientists, ecologists, technologists, students of administration, etc. [that is, to substitute as best they can for the specialties the Bank was chronically lacking]. That this has happened is a tribute to human adaptability, and has produced many useful results. But it is not the same as having real interaction among staff trained in different disciplines. On the contrary, it inspires false confidence that economics is the only knowledge that really matters, and that other disciplines can be "picked up."

The root of the problem lies in the Bank's pattern of external recruitment plus its policy of promotion from within [...].

I also warned Mr. Baum against the typical counter-arguments he might hear opposing the hiring of regular in-house staff by citing the routine work-around of occasionally employing outside consultants. I wrote further:

It will be protested that:

a. The Bank employs consultants of other disciplines, when they are needed.

b. The application to development projects of disciplines other than economics and engineering is not based on a firm conceptual foundation.

' $a$ ' is true but is not a sufficient counter-argument. Sociology is not a specialized discipline to be embodied in a single adviser, or brought in on call to work on problems defined by others. Sociologists should be widely diffused throughout the operational departments of the Bank. So should ecologists. If this need is not perceived at the level of the operating divisions, recruitment should be carried out at higher levels in the regions.

'b' is the statement of a problem, not an excuse for inaction. The Bank, and the developing countries in general, need professionals trained in other disciplines who have a strong familiarity with the needs [of the client countries]. If these people do not exist in sufficient numbers, the Bank should make special efforts to give them the necessary experience, through participation in Bank missions, research projects, EDI courses, or 
even training fellowships to work as quasi-staff members. The cost to the Bank will be repaid [...] by the new dimension they will bring to Bank work, even as they are being trained, and as an investment in the quality of future projects. ${ }^{4}$

\section{The Response of Senior Bank Management}

Baum's response to my memo was faster and more far-reaching than I had expected. He circulated my memo to the Directors of all sector departments in CPS, and convened a meeting for discussing the issue. In fact, I shouldn't have been surprised, because his record on this issue was consistent: he had from the outset personally supported the hiring of the first full-time sociologist into the Central Projects Staff (CPS), of which he was the head. ${ }^{5} \mathrm{He}$ was also aware that Michael Cernea's department was very satisfied with his work, so my memo met a very receptive ear. He asked that I lead the meeting discussion with my memo's argument that employing a significant number of trained social specialists throughout the Bank would enhance project quality. Preparing for the meeting, each director had to focus - in some cases for the first time- on the role of the non-economic social sciences in the operations for which they had responsibility, and to consult with their staff on the use of professional social knowledge in their operations. And, of course, being familiar with the tight way Mr. Baum ran our vice presidency, the Directors knew that he would ask them to report on their follow-through.

The debate that followed was memorable. Fortunately, I have the written minutes of that January 9, 1979 meeting, written by my colleague Sushil Bhatnagar. ${ }^{6}$ In what follows, I'm using these minutes extensively.

My argument began with an undisputable fact: the almost total absence, with one exception, of trained social specialists on Bank staff. Further, I also argued that when economists try to substitute and speak for sociological disciplines, it is not the same as having "real interaction of staff who are trained in different disciplines and are able to look at a given situation from different perspectives", 7 due to their different knowledge lenses. As a result, "sociological or technological issues too often surface

\footnotetext{
${ }^{4}$ Charles Weiss to Mr. Warren C. Baum (through Herman G. van der Tak). Disciplinary Balance of Bank Staff. Office Memorandum, January 3, 1979.

${ }^{5}$ The same perspective led Warren Baum to write, jointly with Stokes Tolbert, a comprehensive book on investing in development, which contained a strongly worded argument in favor of carrying out social assessments in all projects. (See Warren C. Baum and Stokes M. Tolbert, Investing in Development (Baltimore: Johns Hopkins Press, 1985.)

${ }^{6}$ Sushil K. Bhatnagar (Office of the VP Project Staff) to Department Directors and Projects Advisory Staff in Central Projects Staff. "Disciplinary Balance of Bank Staff." Office Memorandum, January 9, 1979. Present in the meeting were: Messrs. Baum, van der Tak, Aklilu, Fuchs, Gordon, Jaycox, Kanagaratnam, Lejeune, Rovani, Sadove, Tolbert, Willoughby, Yudelman, Dosik, Hardy, Lee, Lethem, Morse, Raizen, Ray, Weiss, Bhatnagar. (3 pages.)

${ }^{7}$ Charles Weiss, in Sushil K. Bhatnagar, idem. page 1. (All further quotations in italics are from Sushil's Bathnagar's memorandum with minutes for the World Bank's files.)
} 
late in the project cycle or are not seen at all, while policy papers and research proposals do not benefit from a truly multi-disciplinary review"; and I placed into discussion the proposal that the Bank recruit young sociologists or "technologically oriented generalists" just as it recruits young economists.

More than I expected, virtually all the directors of the Bank's central sectoral departments (just one exception) embraced my argument. Some indicated that they were incorporating at least some sociological insights into their work and took the opportunity to shine before Mr. Baum and their peers. Others defended themselves, invoking the limited manpower with which they had to accomplish their core tasks.

Montague Yudelman, the director of the Agriculture and Rural Development Department and a McNamara protégé, pointed out that his department was the only Department in CPS that had a professional sociologist as a full time staff member. He gave a pretty detailed and highly favorable description of Cernea's initiatives in his Department, and also reported that Cernea he "provides direct operational support to regional divisions for sociological issues in projects" The work of Michael Cernea, he said, "has raised staff consciousness regarding such issues as the 'culture of poverty,' compulsory resettlement, and the institutional premises to community cooperation" through a series of well-attended sociological seminars offered by invited scholars in anthropology and sociology on such subjects as irrigation, land settlement, livestock and pastoral populations, small size credits, agricultural research, etc. ${ }^{8} \mathrm{He}$ further reported that "Cernea also has developed a roster of consultant sociologists and anthropologists (available from him on request) and organized a handful of staff members who are trained in sociology-most of whom make little use of their training on the job (!)—into an informal 'sociological group' for the exchange of work-related experience."

Kim Jaycox, the director of the Urban Projects Department, who like Yudelman had been specially tasked by McNamara to develop an innovative approach to alleviating poverty, reported that local sociologists were being used effectively as consultants in the urban sector. Jaycox suggested that general anthropologists (as distinct from those defined mainly by their specific country knowledge) were suitable primarily for work such as development of guidelines and standards and for developing staff sensitivities to social and cultural problems. He proposed that the Bank develop "stables" of available anthropologist and sociologist consultants with experience in important areas of Bank work. Jaycox agreed that "a narrow disciplinary mix meant narrow project design and late recognition of externalities." Aklilu Lemma, the director of the Education Department, supported Yudelman and Jaycox and added that in his opinion, this last point was a major long-run problem of the Bank.

\footnotetext{
${ }^{8}$ Several of these commissioned papers, authored by outside social scientists and enriched after being discussed in open seminars with Bank staff, are included in the volume: "Putting People First. Sociological Variables in Rural Development": (New York: Oxford University Press, 1985; 1991 2nd ed.)
} 
Stokes Tolbert, the director for tourism projects, supported the memo's assertion that the Bank should have staff who were able to identify and define broad sociological issues and who could assess the qualifications and supervise the work of non-staff sociological consultants who were hired to work on the design and supervision of specific projects. Other directors agreed with the importance of sociological issues, but were more inclined to stress the importance of raising the consciousness of Bank staff through reviewing projects and holding seminars, rather than by hiring staff with specific training in sociology.

The main dissent from this viewpoint came from Chris Willoughby, the director of transportation, who said that he did not believe that inattention to sociology and anthropology was a serious problem for the Bank. He argued that the Bank already had many staff members with "broad training" and that the transportation staff under his supervision were well equipped to deal with the broader aspects of Bankfinanced projects.

At the meeting's end, Baum summarized the discussion with firm conclusions: "The Bank needed more exposure to disciplines like sociology and technology (broadly construed) and ... the demand for experts in these areas would increase as staff were more exposed to these perspectives and grew to understand their relevance to Bank work."

Copies of the minutes of the meeting were sent to all members of the Bank's top management, including Mr. McNamara's personal assistant, Caio Koch-Weser, and to all the Bank's Operational Vice Presidents: Messrs. Stern, Baum, Barletta, Benjenk, Chadenet, Chaufournier, W. Clark, Hopper, Husain, Wapenhans, Weiner, and Gabriel, as well as to the director of Bank Personnel Dept., Mr. Jennings, to William Clark, the Head of Public Relations, and to the official liaison with the Bank Executive Directors, Mr. Hattori. This was the routine pattern of distribution for the minutes of all meetings of CPS directors. Its importance in this instance lay in the fact that the policies decided in the meeting would lead to changes in recruitment policy, and that there were likely to be specific follow-up measures to assess both implementation and impacts.

Baum was clearly determined to push the Bank forward on this issue. After some time, CPS established a recruitment committee chaired by Michael Cernea and given the mandate to help the Personnel Department to recruit and hire social specialists from outside the Bank by interviewing the individuals identified and selected by the Personnel Department and assessing their professional quality and suitability for Bank work. That committee had the authority to endorse or reject these candidates on professional grounds.

\section{The Road to Critical Mass}

Warren Baum's support mattered much in the Bank of that time. He understood that the Bank needed to treat in a professional manner the social dimensions and determinants of development, and not only the economic and technical drivers of 
development. For this, he agreed that it was not enough to have a few heroic pioneers doing their best to spread the gospel of sociology and anthropology to a staff of thousands of seasoned economic and engineering professionals. Nor was it enough to sporadically use temporary consultants, nor to resort to economists ready to improvise and substitute for social science professionals, despite their lack of training in non-economic social sciences.

On the contrary, spreading ideas inside a large scale bureaucratic organization required an uphill struggle against the prevailing Bank economic culture in order to pursue a broader vision of social development, including but not limited to economic growth. It required the creation of an in-house "epistemic community" that spread the understanding of new concepts across the institution along pathways of communication not dictated by the formal organizational structure. ${ }^{9}$ The new epistemic community attracted the attention of independent researchers who published studies that described it in the literature as a textbook example of the impact of informal networks in changing the intellectual culture of a large and well-established organization. ${ }^{10}$ In time, the ideas and policies that they promoted also spread to other development assistance agencies and influenced their operations.

Almost immediately after this meeting, the Bank's readiness to recruiting such specialists as regular staff increased. The Bank had already identified a number of social specialists that could do good work, and had employed them as consultants. Among this ready pool of new recruits was, for instance, Maritta Koch-Weser, who since 1997 had been successfully and repeatedly employed for 3 years as a consultant; now, in 1980, she received an expedited offer to become a regular staff member. The quality and creativity of her work made her a leading anthropologist in the Bank, and she later rose to high managerial responsibilities. Another excellent former consultant, the cultural anthropologist Shelton (Sandy) Davis, was hired in 1980 as a regular staff; he was to become the in-house champion of attention to indigenous communities inhabiting lands in which the World Bank-financed development projects. As more anthropologists and sociologists became Bank staff, the reasons for recruiting similarly trained and talented professionals became more convincing to skeptics.

As is described in other chapters of this book, throughout the 1980s this group pushed up energetically, step by step, a number of important social policies, and thus prodded the Bank to broaden its development paradigm from purely "economic growth" or "economic development" to the concept, language, policies and practices of "social development." Due to the prominence of the Bank and its intellectual leadership among MDBs and other development aid agencies, this broader social development model spread, to the ultimate benefit of poor people in the developing countries. The prompt and energetic response of Warren Baum to the memo I had

\footnotetext{
${ }^{9}$ See Peter M. Haas, Epistemic communities and international policy coordination. International Organization 46(1), 1-35 (1992).

${ }^{10}$ See Kardam, Nuket. 1993. "Development Approaches and the Role of Policy Advocacy: The Case of the World Bank", World Development 21 (11): 1773-786.
} 
written as a result of Michael Cernea's initiative had broken a bottleneck to the achievement of a critical mass of anthropologists and sociologists in the World Bank and in other development assistance institutions.

Charles Weiss has an $\mathrm{AB}$ in chemistry and physics, summa cum laude, and a $\mathrm{PhD}$ in chemical physics and biochemistry, both from Harvard University. He was appointed in 1971 as the Bank's first Science and Technology Advisor, and served in this capacity until 1985. From 1985 to 1997 he was a Principal of Global Technology Management, Inc., and taught at the Woodrow Wilson School of Princeton University, the School of Advanced International Studies of Johns Hopkins University, the University of Pennsylvania, and the Foreign Service Institute of the U.S. Department of State. Dr. Weiss became Distinguished Professor of Science, Technology and International Affairs (STIA) at the Walsh School of Foreign Service at Georgetown University in 1997, serving as the Director of STIA until 2006. On his retirement in 2014, the annual medal awarded to the outstanding STIA graduate was renamed in his honor. He now holds the title of Distinguished Professor Emeritus. Dr. Weiss was elected a Fellow of the American Association for the Advancement of Science (AAAS), and was also a Visiting Scholar with the Center for Science Diplomacy. Dr. Weiss has published several books, most recently: Structuring an Energy Technology Revolution (MIT Press, 2009), and Technological Innovation in Legacy Sectors (Oxford University Press, 2015), both with co-author William Bonvillian, and Science, Technology and the World We Want (Oxford University Press, 2021). Dr. Weiss has published articles and lectured on a broad range of topics, including innovation policy, scientific uncertainty, environmental policy, and science and technology in developing and emerging economies. He has lectured at numerous universities, including Harvard, the University of California (Berkeley), the Massachusetts Institute of Technology, Jawaharlal Nehru University (Delhi), Makerere University (Kampala, Uganda), the University of Sao Paulo and the Graduate Research Institute for Policy Studies (Tokyo).

Open Access This chapter is licensed under the terms of the Creative Commons Attribution 4.0 International License (http://creativecommons.org/licenses/by/4.0/), which permits use, sharing, adaptation, distribution and reproduction in any medium or format, as long as you give appropriate credit to the original author(s) and the source, provide a link to the Creative Commons license and indicate if changes were made.

The images or other third party material in this chapter are included in the chapter's Creative Commons license, unless indicated otherwise in a credit line to the material. If material is not included in the chapter's Creative Commons license and your intended use is not permitted by statutory regulation or exceeds the permitted use, you will need to obtain permission directly from the copyright holder.

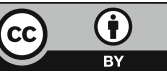

